\title{
Clinical and sociodemographic profile of cervical cancer patients visiting a tertiary care hospital in India
}

\author{
Preethi $A^{1^{*}}$, K V S Latha² , S Suresh Kumar ${ }^{3}$, E Senthil Kumar ${ }^{4}$ \\ ${ }^{1}$ PG, ${ }^{2}$ Professor \& HOD, ${ }^{3,4}$ Assistant Professor, Department of Medical Oncology, Madras Medical College \& RGGGH, Chennai 600003, INDIA. \\ Email: pritams.2004@gmail.com
}

Abstract Background: Cervical cancer, the most common genital tract malignancy, is a major health burden in developing countries. Understanding the clinical and sociodemographic profile of patients helps in planning control measures and treatment facilities. Aim: To determine the sociodemographic and clinical profile of cervical cancer patients and study their association with tumor related factors. Methods and Materials: This is a retrospective study of 400 cervical cancer patients visiting a tertiary care hospital in Chennai during the period of January 1,2015 to June 30, 2018. Data was analysed using descriptive statistics and Chi square and Kruskal Wallis test were used to assess the relationship. Results: The median age was found to be 54 years. Around $54 \%$ were illiterate and $92 \%$ had squamous cell carcinoma. Only $5 \%$ had early stage disease and $81.5 \%$ did not have any prior treatment. Concomitant comorbidities were seen in $29.5 \%$ of the patients with hypertension being the most common $(16.75 \%)$. The stage of the disease was found to be significantly $(\mathrm{p}<0.05)$ associated with age and educational status. Conclusion: This study shows important baseline characteristics of cervical cancer patients, which can help in planning for optimum utilization of hospital services and treatment facilities, especially in developing countries like India.

Key Word: cervical cancer.

*Address for Correspondence:

Dr Preethi A, PG, Department of Medical Oncology, Madras Medical College \& RGGGH, Chennai 600003, INDIA.

Email: pritams.2004@gmail.com

Received Date: 04/04/2020 Revised Date: 12/05/2020 Accepted Date: 26/07/2020

DOI: https://doi.org/10.26611/10121532

This work is licensed under a Creative Commons Attribution-NonCommercial 4.0 International License. $(\boldsymbol{C c})$ EY-NC

\begin{tabular}{|l|l|}
\hline \multicolumn{2}{|c|}{ Access this article online } \\
\hline Quick Response Code: & Website: \\
& www.medpulse.in \\
& \\
\hline
\end{tabular}

\section{INTRODUCTION}

Cervical cancer is the most common female genital tract malignancy and a major health problem in developing countries ${ }^{1}$. The majority of the cases are seen in the developing countries. It is estimated that the incidence of cervical cancer is approximately 1 in 53 Indian women during their lifetime ${ }^{2-3}$. The exact cause of cervical cancer is still unknown. However it is more common in women living under lower socioeconomic conditions and with lack of education. The risk factors related to cervical cancer are exposure to human papilloma virus, early age at marriage, early age at first sexual intercourse, more number of sexual partners, high parity, smoking and several others ${ }^{4-7}$. In India, large section of population belongs to below poverty line lacking awareness and access to cervical cancer screening, diagnosis and treatment facilities. Cervical cancer accounts for almost $17 \%$ of the cancer deaths among women aged 30-70 years ${ }^{3}$. Studying the clinical and sociodemographic profile, additional comorbidities along with patient presentation remains the first step to plan control measures. Hence this study has been conducted in a tertiary care hospital in India to study the clinical and sociodemographic profile of cervical cancer patients.

\section{SUBJECTS AND METHODS \\ STUDY DESIGN}

This is a retrospective study based on hospital records of Department of Medical Oncology, Institute of Obstetrics and Gynaecology, Chennai, India. 


\section{STUDY POPULATION:}

Hospital medical records of 400 cervical cancer patients who had reported to Department of Medical Oncology, Institute of Obstetrics and Gynaecology, Chennai, during the period of January 1, 2015 to June 30, 2018 were retrospectively analyzed. Patients who were diagnosed before the study period and already on treatment were not included in the study.

\section{DATA COLLECTION}

The clinical and sociodemographic details obtained from hospital medical records were age, religion, marital status, education, occupation status, treatment history, parity, menopausal status, symptoms, stage, tumor histology, performance status and presence of comorbidities.

\section{STATISTICAL ANALYSIS}

Data was analyzed by using descriptive statistics. Chisquare test and Kruskal-Wallis test were used for assessing relationship between variables. $\mathrm{P}<0.05$ was considered statistically significant.

\section{RESULTS}

The total number of patients included in the study is 400 . Table 1 shows the sociodemographic profile of carcinoma cervix patients. Most of the patients belonged to 45-54 age group (32\%) followed by 55-64 (29\%) and only $19.75 \%$ were below 45 years of age. The median age of patients was 54 years. Majority of the patients were Hindus (85\%) followed by Muslims( $9 \%$ ) and the rest were from other communities. More than half were illiterate $(54 \%)$ and only $3.5 \%$ completed college education. $76 \%$ were married and $23.5 \%$ were widows and $0.5 \%$ were unmarried. Nearly $75 \%$ had 2 to 4 children with $15 \%$ having more than 4 children while only $9.75 \%$ reported to have less than 2 children. Postmenopausal patients comprised about $73.75 \%$ of the study population. Most of the patients were homemakers $(87 \%)$ with $4.5 \%$ working in agricultural fields. About $18.5 \%$ had taken treatment for cancer previously before reporting to this centre. Symptomatology, clinical stage, histology, performance status and associated comorbid conditions described the clinical profile of the cervical cancer patients(Table 2). Most common symptom was bleeding per vaginum (81.25\%) followed by abdominal pain (78.5\%), white discharge (53.25\%), loss of appetite and weight (49.5\%), back pain (44\%) and others like post coital bleeding, burning micturition and difficulty to defecate. Stage-wise analysis had shown that most of the patients belonged to Stage IIB (45.75\%) and IIIB (42\%). Majority of the patients had squamous cell carcinoma (92\%) followed by adenocarcinoma (5.75\%). Eastern Cooperative Oncology Group scale was used to measure the performance status. This revealed that most of the patients $(68 \%)$ were able to carry out all normal activities without any restrictions and only $0.75 \%$ were bedridden. Around 118 patients $(29.5 \%)$ had associated comorbidities like hypertension, diabetes, HIV, hypothyroidism, bronchial asthma and tuberculosis, the most common being hypertension (16.75\%) followed closely by diabetes mellitus (16.5\%). An analysis to find any association between stage and sociodemographic factors such as age and education level was also done. There was significant association between stage of the disease with both age and educational status.

\begin{tabular}{|c|c|}
\hline Sociodemographic factor & Number of patients(\%) \\
\hline \multicolumn{2}{|l|}{ Age group (years) } \\
\hline$<35$ & $9(2.25)$ \\
\hline $35-44$ & $70(17.5)$ \\
\hline $45-54$ & $128(32)$ \\
\hline $55-64$ & $116(29)$ \\
\hline $65-74$ & $64(16)$ \\
\hline 75 and above & $13(3.25)$ \\
\hline \multicolumn{2}{|l|}{ Religion } \\
\hline Hindu & $340(85)$ \\
\hline Muslim & $36(9)$ \\
\hline Christian & $14(3.5)$ \\
\hline Others & $10(2.5)$ \\
\hline \multicolumn{2}{|l|}{ Education level } \\
\hline Illiterate & $216(54)$ \\
\hline Primary & $88(22)$ \\
\hline Middle & $10(2.5)$ \\
\hline Secondary & $72(18)$ \\
\hline College and above & $14(3.5)$ \\
\hline \multicolumn{2}{|l|}{ Marital Status } \\
\hline Married & $304(76)$ \\
\hline Widow & $94(23.5)$ \\
\hline Others (unmarried/divorced) & $2(0.5)$ \\
\hline \multicolumn{2}{|l|}{ Parity } \\
\hline$<2$ & $39(9.75)$ \\
\hline $2-4$ & $301(75.25)$ \\
\hline$>4$ & $60(15)$ \\
\hline \multicolumn{2}{|l|}{ Menopausal status } \\
\hline Premenopausal & $105(26.25)$ \\
\hline Postmenopausal & $295(73.75)$ \\
\hline \multicolumn{2}{|l|}{ Occupation status } \\
\hline Homemakers & $348(87)$ \\
\hline Service & $14(3.5)$ \\
\hline Retired & $5(1.25)$ \\
\hline Agriculture & $18(4.5)$ \\
\hline Others(maids/daily wage labourers) & $15(3.75)$ \\
\hline \multicolumn{2}{|l|}{ Treatment History } \\
\hline Prior treatment & $74(18.5)$ \\
\hline No prior treatment & $326(81.5)$ \\
\hline
\end{tabular}

Table 2: Clinical Profile of Cervical cancer patients:

\begin{tabular}{cc}
\hline Clinical Factors & Number of Patients (\%) \\
\hline Symptoms & \\
Abdominal pain & $314(78.5)$ \\
Back Pain & $176(44)$ \\
Post coital bleeding & $28(7)$ \\
\hline
\end{tabular}




\begin{tabular}{|c|c|c|c|c|c|}
\hline \multicolumn{3}{|c|}{ Bleeding per vaginum } & \multicolumn{3}{|c|}{$325(81.25)$} \\
\hline \multicolumn{3}{|c|}{ White discharge } & \multicolumn{3}{|c|}{$213(53.25)$} \\
\hline \multicolumn{3}{|c|}{ Burning micturition } & \multicolumn{3}{|c|}{$76(19)$} \\
\hline \multicolumn{3}{|c|}{ Difficulty to defecate } & \multicolumn{3}{|c|}{$21(5.25)$} \\
\hline \multicolumn{3}{|c|}{ Loss of appetite/ loss of weight } & \multicolumn{3}{|c|}{$198(49.5)$} \\
\hline \multicolumn{6}{|c|}{ Stage } \\
\hline \multicolumn{3}{|c|}{ IB } & \multicolumn{3}{|c|}{$18(4.5)$} \\
\hline \multicolumn{3}{|c|}{ IIA } & \multicolumn{3}{|c|}{$2(0.5)$} \\
\hline \multicolumn{3}{|c|}{ IIB } & \multicolumn{3}{|c|}{$183(45.75)$} \\
\hline \multicolumn{3}{|c|}{ IIIA } & \multicolumn{3}{|c|}{$9(2.25)$} \\
\hline \multicolumn{3}{|c|}{ IIIB } & \multicolumn{3}{|c|}{$168(42)$} \\
\hline \multicolumn{3}{|c|}{ IVA } & \multicolumn{3}{|c|}{$5(1.25)$} \\
\hline \multicolumn{3}{|c|}{ IVB } & \multicolumn{3}{|c|}{$15(3.75)$} \\
\hline \multicolumn{6}{|c|}{ Histology } \\
\hline Squamo & us cell carcinom & & & $8(92)$ & \\
\hline Ade & hocarcinoma & & 23 & (5.75) & \\
\hline & Others & & & $2.25)$ & \\
\hline Performa & nce status (ECO & & & & \\
\hline & 0 & & & $2(68)$ & \\
\hline & 1 & & & (13) & \\
\hline & 2 & & & 2.25) & \\
\hline & or more & & & $0.75)$ & \\
\hline & Jnknown & & & $(16)$ & \\
\hline Como & bid Conditions & & & & \\
\hline & pertension & & 671 & 16.75) & \\
\hline Diab & etes Mellitus & & 66 & $(16.5)$ & \\
\hline Hyp & othyroidism & & & $2(3)$ & \\
\hline & HIV & & & (1.5) & \\
\hline Others (TB & Bronchial Asth & na) & & (1.5) & \\
\hline $\begin{array}{l}\text { Tak } \\
\text { Stage }\end{array}$ & 3: Comparison o & $\frac{\text { age }}{\text { ars) }}$ & $\frac{\text { ith respect } t}{\text { Range (yea }}$ & $\frac{\text { to stą }}{\text { trs) }}$ & P value \\
\hline 1 & 49 & & 44 & & $<0.001$ \\
\hline II & 54 & & 50 & & \\
\hline III & 56 & & 55 & & \\
\hline IV & 58.5 & & 52 & & \\
\hline All stages & 54 & & 65 & & \\
\hline $\begin{array}{c}\text { Illiterate } \\
\text { n(\%) }\end{array}$ & $\begin{array}{c}\text { Primary } \\
n(\%)\end{array}$ & $\begin{array}{r}\text { Secc } \\
\text { ab }\end{array}$ & $\begin{array}{l}\text { ondary and } \\
\text { ove, } n(\%)\end{array}$ & Total & $\begin{array}{c}P \\
\text { value }\end{array}$ \\
\hline $21(9.72)$ & $17(17.3)$ & & $4(16.27)$ & 52 & 0.010 \\
\hline 69 (31.9) & $36(36.7)$ & & $34(39.5)$ & 139 & \\
\hline 105 (48.6) & 38 (38.77) & & $1(36.04)$ & 174 & \\
\hline $21(9.72)$ & $7(7.14)$ & & 7 (8.13) & 35 & \\
\hline 216 & 98 & & 86 & 400 & \\
\hline
\end{tabular}

\section{DISCUSSION}

India is a very diverse country when it comes to ethnicity. In contrast to the developed countries of the world, cervical cancer is a major health issue faced in India. Conventional cytology screening programs have reduced the incidence of cervical cancer in developed countries ${ }^{11,12}$. However, owing to the low availability of resources in India, a high risk of developing cervical cancer still remains. Hence the clinical profile of cervical cancer patients is very essential for early diagnosis and treatment which is important for cancer control. The median age of cervical cancer patients in this study was 54 years, which is almost similar to the average age reported in Sankaranarayanan et al. ${ }^{13}$. in his study of 452 cervical patients conducted by Kerala. The average age of patients was higher than that which was reported by other researchers ${ }^{14}$. Relative lack of awareness and non-availability of screening facilities for cervical cancer in our country have led to higher incidence in older age groups ${ }^{15-16}$. Majority of them belonged to the age group 45-54 year followed by 55-64 which was similar to other research works in our country ${ }^{17-22}$. Median age of the higher stage patients was found to be higher than the median age of the lower stage patients, as with Flores-Luna et al. ${ }^{14}$. The higher median age seen in patients with advanced stage may be due to late diagnosis of cancer. It could also point towards the differences in awareness of cervical cancer symptoms in elderly and also differences in healthcare seeking behaviour ${ }^{23}$. Thus, improving the knowledge, skills and confidence of elderly so that they present early with symptoms might help to downstage the cervical cancer in older women and further improve their survival. In this study, $54 \%$ were illiterate and only $3.5 \%$ had a college qualification and above. The association between stage and educational status was studied. This is in concordance with many studies which have proven illiteracy to be a risk factor for carcinoma cervix ${ }^{24-26}$. Lack of education is linked with early marriage and high parity which are also risk factors for carcinoma cervix. Thus improving the educational status of women in India can be an important component of holistic approach for control of cervical cancer in India. Improvement of living standards and formulation of public health policies aimed at improving awareness along with cancer screening programs help in reducing cervical cancer in India ${ }^{24}$. In our study, $76 \%$ were married which was higher than $62.4 \%$ which was reported in Sankaranarayanan et al. ${ }^{13}$, but lower than $88.61 \%$ which was reported by Thulaseedharan et $a l .{ }^{18}$. Among all patients, $29.5 \%$ had associated comorbidities, of which hypertension was the most common. The prevalence of comorbid conditions in this study was higher than that was reported by Ibfelt et al. ${ }^{19}$. The distribution of religion reported in this study showed similar results in other studies ${ }^{15}$. In our study, only $3.5 \%$ belonged to stage I and around $50 \%$ had advanced stage diseases (III and IV). Similar stage-wise distributions was seen in Nandakumar et al. ${ }^{16}$ and Shrivastava et al. ${ }^{27}$. Squamous cell carcinoma was reported in around $92 \%$ of the patients which was similar to several other researches ${ }^{19,28}$. Only $68 \%$ reported to belong to ECOG score 0 in terms of performance status which was below the values reported by Sankaranarayanan et al. ${ }^{13}(81 \%)$ and Vishma Baliyada Kaverappa et al. ${ }^{26}$. Several limitations of this study have to be taken into account. Important 
characteristics like socioeconomic status and family income were not considered. The time of incidence of comorbid conditions was not reported. These limitations were present because the study was based on secondary data and the information in medical records were only recorded. However, the importance of this study lies in the fact that very few studies have described sociodemographic and clinical profile of patients in India and this study also explores the relationship between tumor factors and patient characteristics.

\section{CONCLUSION}

In our country, very few studies are present describing clinical profile of cancer patients visiting health care facilities. Understanding it can help ensure proper accessibility and utilization of hospital care services in resource poor countries like India. The information gathered can be helpful in formulating proper guidelines, public health policies and implementation of cancer control programs.

\section{REFERENCES}

1. Awodele O, Adeyomoye AA, Awodele DF, Kwashi V, Awodele IO, Dolapo DC, et al.. A study on cervical cancer screening amongst nurses in Lagos university teaching hospital, Lagos, Nigeria. J Cancer Educ 2011;26:497-504.

2. Ferlay J, Soerjomataram I, Ervik M, Dikshit R, Eser S, Mathers C, et al.. GLOBOCAN 2012 v1.0, Cancer Incidence and Mortality Worldwide: IARC Cancer Base No. 11. Lyon, France: International Agency for Research on Cancer; 2013.

3. Institute for Health Metrics and Evaluation. The Challenge Ahead: Progress in Breast and Cervical Cancer. Institute of Health Metrics and Evaluation; 2011.

4. International Collaboration of Epidemiological Studies of Cervical Cancer. Comparison of risk factors for squamous cell carcinoma and adenocarcinoma of the cervix. Collaborative study of individual data on 8097 women with squamous cell carcinoma and 1374 women with adenocarcinoma from 12 epidemiological studies. Int J Cancer 2007; 120:885-91.

5. Franceschi S, Plummer M, Clifford G, de Sanjose S, Bosch $\mathrm{X}$, Herreo $\mathrm{R}$, et al.. Differences in the risk of cervical cancer and human papilloma virus infection by education level. Br J Cancer 2009; 101:865-70.

6. Green J, Berrington de Gonzalez A, Sweetland S, Beral V, Chilvers C, Crossley B, et al.. Risk factors for adenocarcinoma and squamous cell carcinoma of the cervix in women aged 20-44 years: The UK national casecontrol study of cervical cancer. $\mathrm{Br} \mathrm{J}$ Cancer 2003;89:2078-86.

7. Rajkumar T, Franceschi S, Vaccarella S, Gajalakshmi V, Sharmila A, Snijders PJ, et al.. Role of paan chewing and dietary habits in cervical carcinoma in Chennai, India. $\mathrm{Br}$ J Cancer 2003;88:1388-93.

8. Balasubramanium G, Sushama S, Rasika B, Mahantshetty U. Hospital-based study of endometrial cancer survival in Mumbai, India. Asian Pac J Cancer Prev 2013;14:977-80.
9. Balasubramanium G, Talole S, Mahantshetty U, Saoba S, Shrivastava S. Prostate cancer: A hospital based survival study from Mumbai, India. Asian Pac J Cancer Prev 2013;14:2595-8.

10. Ganesh B, Swaminathan R, Mathew A, Sankaranarayanan $\mathrm{R}$, Hakama M. Loss-adjusted hospital and population based survival of cancer patients. IARC Sci Publ 2011;162:15-21.

11. IARC. Handbooks on Cancer Prevention. Cervix Cancer screening. Vol 10. Lyon:IARC Press ;2004.

12. Sankaranarayanan R, Budukh Am, Rajkumar R. Effective screening programs for cervical cancer in low and middle income developing countries. Bull World Health Organ 2001;79:954-62.

13. Snakaranarayanan R, Nair MK, Jayaprakash PG, Stanley $\mathrm{G}$, Varghese C, Ramadas V, et al.. Cervical Cancer in Kerala: A hospital registry based study on survival and prognostic factors. Br J Cancer 1995;72:1039-42.

14. Flores-Luna L, Slaazar-Martinez E, Escudero-De los Rios P, Gonzalez-Lira G, Zamora-Munoz S, Lazcano-Ponce E, et al. . Prognostic factors related to cervical cancer in Mexican women. Int J Gynaecol Obstet 2001;75:33-42.

15. Kaverappa VB, Prakash B, Kulkarni P, Renuka M. Sociodemographic profile of patients with cervical cancer in a tertiary care cancer hospital in Mysuru, Karnataka. Int J Med Sci Public Health 2015;71:1348-52.

16. Nandakumar A, Anantha N, Venugopal TC. Incidence, mortality and survival in cancer of the cervix in Bangalore, India. Br J Cancer 1995;71:1348-52.

17. Rajarao P, Hemanth Kumar B. Study of socio demographic profile of cancer cervix patients in tertiary care hospital, Karimnagar (Andhra Pradesh). Int J Biol Med Res 2012;3:2306-2310.

18. Thulaseedharan JV, Malila N, Hakama M, Esmy PO, Cheriyan M, Swaminathan R, et al.. Socio demographic and reproductive risk factors for cervical cancer - A large prospective cohort study from rural India. Asian Pac J Cancer Prev 2012;13:2991-5.

19. Ibfelt EH, Kjaer Sk, Hogdall C, Steding-Jessen M, Kjaer TK, Osler M, et al.. Socioeconomic position and survival after cervical cancer: Influence of cancer stage, comorbidity and smoking among Danish women diagnosed between 2005 and 2010. $\mathrm{Br} \mathrm{J}$ Cancer 2013;109:2489-95.

20. National Cancer Registry Programme (NRCP), Indian Council of Medical Research (ICMR). An Assessment of the Burden and Care of Cancer Patients: Consolidated report of Hospital based Cancer Registries, 2001-2003. Bangalore: NRCP, ICMR; 2007.

21. Rajesh N, Sreelakshmi K, Ramesh K. Sociodemographic profile of patients with cancer of cervix attending tertiary care hospital. Int J Sci Res 2014;3:331-2.

22. Fotra R, Gupta S. Sociodemographic risk factors for cervical cancer in Jammu region of J and K state of India first ever report from Jammu. Indian J Sci res 2014;9:10510.

23. Ertem G. Awareness of cervical cancer risk factors and screening behaviour among nurses in a rural region of Turkey. Asian Pac J Cancer Prev 2009;10:735-8.

24. Thakur A, Gupta B, Gupta A, Chauhan R. Risk factors for cancer cervix among rural women of a hilly state: A casecontrol study. Indian J Public Health 2015;59:45-8. 
25. Patil V, Wahab SN, Zodpey S, Vasudeo ND. Development and validation of risk scoring system for prediction of cancer cervix. Indian J Public Health 2006;50:38-42.

26. Kaverappa VB, Boralingaiah P, Kulkarni P, Manjunath R. Determinants of survival among patients with cervical cancer: A hospital based study. Natl J Community Med 2015;6:4-9.

27. Shrivastava S, Mahantshetty U, Engineer R, Tongaonkar $\mathrm{H}$, Kulkarni J, Dinshaw K. Treatment and outcome in cancer cervix patients treated between 1979 and 1994: A single institutional experience. J Cancer Res Ther 2013;9:672-9.

28. Kumar S, Rana ML, Verma K, Singh N, Sharma AK, Maria Ak, et al.. PrediQt-cx: Post treatment health related quality of life prediction model for cervical cancer patients. PLoS One 2014;9:e89851.

\section{Source of Support: None Declared Conflict of Interest: None Declared}

Policy for Articles with Open Access:

Authors who publish with MedPulse International Journal of Gynaecology, (Print ISSN: 2579-0870) (Online ISSN: 2636-4719) agree to the following terms: Authors retain copyright and grant the journal right of first publication with the work simultaneously licensed under a Creative Commons Attribution License that allows others to share the work with an acknowledgement of the work's authorship and initial publication in this journal.

Authors are permitted and encouraged to post links to their work online (e.g., in institutional repositories or on their website) prior to and during the submission process, as it can lead to productive exchanges, as well as earlier and greater citation of published work. 